ISSN: 2594-4827

\title{
PAPEL DAS METODOLOGIAS ATIVAS NA FORMAÇÃO HUMANA INTEGRAL NA EDUCAÇÃO PROFISSIONAL E TECNOLÓGICA ${ }^{1}$
}

\author{
Robson Freitas da Silva ${ }^{2}$ \\ Sarah Correia de Souza ${ }^{3}$ \\ Maria Francisca Morais de Lima ${ }^{4}$
}

\section{RESUMO}

O presente estudo é fruto de pesquisa bibliográfica e reflexões relativas à aplicação das metodologias ativas no contexto educacional, mais especificamente, quanto à forma por meio das quais os conteúdos são trabalhados em sala de aula, trazendo ainda uma ponderação crítica acerca tanto dos papéis exercidos pelos alunos quanto pelos professores dentro do contexto atual. Em consequência às ideias apresentadas no decorrer do trabalho, advogam a aplicação de metodologias capazes de, não apenas, fazer com que o aluno tenha maior engajamento nas atividades desenvolvidas no cotidiano escolar, como também seja estimulado a detectar ou criar problemas e buscar a aplicabilidade de soluções. A aplicação de metodologias ativas no processo de ensinoaprendizagem representa papel fundamental para a formação humana integral dentro da Educação Profissional e Tecnológica, por esse motivo, o presente trabalho tem por objetivo discutir as Metodologias Ativas como alternativa para as práticas pedagógicas de integração de conhecimentos, possibilitandoassim a construção autônoma do conhecimento. Diante do exposto, vale ressaltar que um profissional ou instituição de Educação Profissional e Tecnológica, que não reconheça a importância e a necessidade de aplicabilidade dessas metodologias, dificilmente atingirá seu objetivo maior que é a formação humana integral de seus alunos.

Palavras-chave: Educação Profissional e Tecnológica; Metodologias Ativas; Proposta Metodológica.

\footnotetext{
${ }^{1}$ Uma versão preliminar desse texto foi apresentada no I Simpósio Amazônico em Educação Profissional e Tecnológica, promovido pelo ProfEPT/IFAM/CMC, realizado em Manaus, Amazonas, nos dias 28 a 29/11/2018.

2 Estudante do Mestrado Profissional em Educação Profissional e Tecnológica do Instituto Federal de Educação, Ciência e Tecnologia do Amazonas. robson.freitas@ifam.edu.br

${ }^{3}$ Estudante do Mestrado Profissional em Educação Profissional e Tecnológica do Instituto Federal de Educação, Ciência e Tecnologia do Amazonas. sarahcorreias@ gmail.com

4 Doutora em Língua Portuguesa. Professorado Mestrado Profissional em Educação Profissional e Tecnológica do Instituto Federal de Educação, Ciência e Tecnologia do Amazonas. afranlima@yahoo.com.br
} 


\begin{abstract}
The present study is the result of a bibliographical research and reflections on the application of active methodologies in the educational context, more specifically, on the way in which the contents are worked in the classroom, bringing also a critical consideration about both the roles played by the students and teachers with in the current context. As a consequence of the ideas presented in the course of the work, they advocate the application of methodologies capable of not only making the student more engaged in the activities carried out in the schoolday-to-day activities, but also being stimulated to detect or create problems and seek the applicability of solutions. The application of active methodologies in the teaching-learning process represents a fundamental role for the integral human formation with in the Professional and Technological Education, for this reason, the present work aims to discuss the Active Methodologies as na alternative to the pedagogical practices of know ledge integration, thus enabling the autonomous construction of know ledge. In view of the above, it is worth mentioning that a professional or institution of Vocational and Technological Education, which does not recognize the importance and the necessity of applicability of these methodologies, Will hard lyachieve its greater objective than the integral human training of its students.
\end{abstract}

Keywords: Professional and Technological Education; Active Methodologies; Methodological Proposal.

\title{
INTRODUÇÃO
}

A Educação Profissional e Tecnológica tem sofrido diversas modificações ao longo do tempo, deixando de ser um mero instrumento assistencialista para tornar-se uma alternativa de destaque entre as modalidades educacionais que se propõem a serem promotoras de transformação social. No entanto, ainda há muito a se conquistar para que esta modalidade alcance seus objetivos, uma vez que não se constrói uma educação de fato transformadora, quando se está preso a metodologias que têm por base a reprodução e que provoquem inquietação e curiosidade no discente.

A educação profissional desenvolvida nos Institutos Federais de Educação vem passando por um processo de ressignificação, uma vez que o docente atua em vários níveis e modalidades de ensino, que exige o desenvolvimento de práticas pedagógicas exitosas, capazes de gerar essa formação humana integral.

Para tanto, discutiremos neste trabalho as transformações ocorridas na Educação Profissional Tecnológica e como as Metodologias Ativas podem ser instrumentos pedagógicos eficientes e uma importante alternativa, não só para o fazer pedagógico 
docente, como um potencial para integraçãodos conhecimentos técnicos e gerais, possibilitando assim a construção autônoma do conhecimento.

\section{EDUCAÇÃO PROFISSIONAL NO BRASIL}

Nos termos da Lei no 9.394/96, a Educação Profissional e Tecnológica, EPT, “[...] integra-se aos diferentes níveis e modalidades de educação e às dimensões do trabalho, da ciência e da tecnologia" (art. 39), abrangendo tanto cursos de formação inicial e continuada ou qualificação profissional, quanto os de educação profissional técnica de nível médio e os de educação profissional tecnológica, seja de graduação ou pósgraduação (art. 39, §2º).

Esse modelo educacional vem sendo, ao longo dos anos, alvo das mais diferenciadas modificações: aquilo que iniciou, conforme os dizeresde Lima e Souza (2017), como um verdadeiro plano educacional destinado aos jovens economicamente desfavorecidos para a concepção de mão de obra operária, hoje é tido como a educação que visa a formação humana integral.

Não se trata de afirmar, todavia, que atualmente a educação profissional não tenha por objetivo a formação de mão de obra para o mundo do trabalho, mas a diferença está no fato de que já não mais se limita a isso. Para além da formação profissional, como o próprio nome já expressa claramente, se tem a precisão de formar o homem em sua integralidade, pois o termo educação tecnológica não se limita à descrição da formação capaz de dar ao indivíduo as qualificações necessárias para o exercício de uma função que atenda aos anseios de determinados setores ou classes, vai além disso, uma vez que:

[...] está baseada numa concepção ampla e universal de educação, que transcende os conceitos fragmentados, pontuais ou direcionados do ensino, aprendizagem e formação, substituindo-os pela integração renovada do saber, do fazer, do saber fazer e do pensar e repensar no saber e no fazer, como objetos permanentes da ação e reflexão crítica da ação. Abrangendo, várias modalidades de formação e capacitação, a educação tecnológica não se caracteriza pela divisão de níveis e graus de ensino, mas pelo caráter global e unificado da formação técnico profissional, integrada aos pressupostos mais amplos da conscientização do trabalhador e da construção de cidadania, dirigida especificamente para a produção social (BARROS, 1997, p. 15 apud DURÃES, 2009, p. 166). 
A formação humana integral

[...] é uma das tarefas educacionais. A tradição nos narra que a cultura ocidental se orienta com base nessa máxima da razão humana. Desde Platão, por exemplo, o homem é instigado a controlar suas paixões e dirigir seu esforço para as virtudes sábias e racionais. Nesse sentido, a educação tem um papel muito bem definido em nossa sociedade. Ela não é considerada apenas como um processo institucional, mas é tida como uma forma de investimento humano. Um investimento dado a partir da promessa pedagógica de uma formação completa do homem [...] (DARIVA; BENETTI, 2016, p. 919).

O papel da EPT no contexto atual é sim, portanto, o de formar o profissional apto a exercer seu ofício no mundo do trabalho, mas não se restringe a isto, vez que a educação profissional de modo isolado não consegue garantir a formação completa do homem.

Há quem entenda, também, que:

[...] agrega-se o termo tecnológica para incluir cursos de graduação, genericamente denominados sob o título de tecnologias, cursos em geral de menor duração do que os bacharelados e licenciaturas, com características próximas aos cursos de formação profissional(DALLABONA; MAYNARDES; FARINIUK, 2016, p. 49).

Vale enfatizar que, no texto original da Lei $n^{\circ}$ 9.394/96 não constava o termo “tecnológica". O termo em questão foi incluído na LDB a partir da criação da Lei $\mathrm{n}^{\circ}$ 11.741/2008 que, além de acrescer à educação profissional o vocábulo em questão, ainda promoveu sua integração a outros níveis e outras modalidades de ensino.

Todavia, se vislumbra como importante, observar que a inserção do mencionado termo no contexto da educação profissional não se limita à mera inclusão de cursos de graduação dentro dessa modalidade educacional.

Ao se falar, portanto, em Educação Profissional e Tecnológica, é possível pensar na educação voltada à formação de pessoas capacitadas a atuar no contexto de produção, mas não se limita à tal. Esses sujeitos advindos da EPT são os habilitados para atuarem além do espaço técnico, mas também para serem capazes de atuar significativamente em seu contexto social, provocando ajustes, mudanças e melhoramentos em suas próprias trajetórias de vida e na daqueles integrantes da comunidade na qual estão inseridos.

Atualmente Educação Profissional e Tecnológica é oferecida no Brasil tanto pela iniciativa privada como, por exemplo, pelo Sistema S, quanto pelo setor público, em 
que se destaca a Rede Federal de Educação Profissional e Tecnológica, compostas pelos Institutos Federais.

De acordo com o Plano Nacional de Educação, instituído pela Lei n ${ }^{\text {0 }}$ 13.005/2014 com vigência até 2024, que estabelece diretrizes, metas e estratégias de concretização no campo da educação, havia um apontamento de 1.775.324 matrículas de Educação Profissional Técnica no ano de 2016 2016, sendo meta para 2024 alcançar o quantitativo de 5.224.584 matrículas. A perspectiva é, portanto, a de expansão dessa modalidade educacional, o que ressalta a importância das discussões acerca do tema. Dentre os pontos de reflexão pertinentes está aquele vinculado à prática docente.

Embora se tenha ciência de que para o alcance das especificidades da EPT diversos são os fatores que podem influenciar positiva ou negativamente, não se pode deixar de ressaltar o papel do professor e de suas práticas educativas nesse contexto de formação humana integral.

\section{PRÁTICAS EDUCATIVAS E SUA IMPORTÂNCIA PARA A FORMAÇÃo INTEGRAL DO DISCENTE}

Entendemos que o professor, com sua prática, é um elemento central no processo educativo. E não se trata de esperar desse profissional o ato heroico de salvar a educação apenas com a sua atividade, eximindo outros profissionais e elementos responsáveis pelo sucesso no processo educacional, mas sim de reconhecer a importância do papel docente para a formação discente, uma vez que, conforme os ensinamentos de Zabala (2018), tudo o que fazemos em sala de aula, por mais ínfimo que possa parecer, interfere na formação dos alunos.

Ademais, ainda que não se tratem de frutos a serem colhidos através do exercício da prática profissional de um indivíduo apenas, se tem que o sucesso educacional, materializado no alcance de seus objetivos certamente não se dará sem o trabalho do professor, especialmente quando se considera que é o docente que lida de modo mais próximo e cotidianamente com o alunado.

Nesse contexto, resta claro que a importância da prática docente não está restrita ao campo da Educação Profissional e Tecnológica, mas sim a toda e qualquer forma/modalidade de construção de saber na qual ele esteja inserido. 
A escola, no contexto contemporâneo, passa por uma série de transformações no que diz respeito à sua missão enquanto instituição social formadora de cidadãos. Cobra-se cada vez mais que ela exerça o papel de proporcionar aos alunos a possibilidade de mobilidade social dentro de um contexto onde os papeis na sociedade são determinados pela capacidade de relacionar-se com o outro e com o mundo de um modo geral através de um posicionamento crítico frente às realidades cotidianas. No contexto escolar, no entanto, ainda encontram-se práticas engessadas, descontextualizadas, como se as práticas sociais fossem desvinculadas da realidade dos alunos(BARBOSA; MÜLLER, 2014).

Insistir no desenvolvimento do trabalho docente objetivando apenas a aprendizagem conceitual, especialmente através dos métodos mais tradicionais de ensino, tais como a aula expositiva - na qual o aluno figura como mero repositório de informações, provavelmente não dá ao aprendiz as ferramentas necessárias para contextualização do saber e a consequente reflexão acerca das realidades cotidianas.

Não se vislumbra aqui rechaçar completamente a aplicação do método tradicional no processo de ensino, uma vez que reconhecida a importância dele, uma vez que

[...] foi a escola tradicional a responsável pela formação acadêmica parcial ou completa de incontáveis profissionais da ciência e da técnica desde o renascentismo até a atualidade. Portanto, inestimável é sua importância em muitos dos aspectos do desenvolvimento humano ao longo do tempo, por exemplo, os aspectos social, cultural, científico, econômico, entre outros. Outrossim, a pedagogia tradicional escora a concepção de todas as outras tendências, já que foi o berço do estudo pedagógico (FARIAS; MAIA, s.d., p. 5)

Mas, a verdade é que a formação humana integral demanda algo ainda maior. É nesse contexto que ganha relevância a análise das metodologias ativas de ensino aprendizagem, pois elas:

[...] têm o potencial de despertar a curiosidade, à medida que os alunos se inserem na teorização e trazem elementos novos, ainda não considerados nas aulas ou na própria perspectiva do professor. Quando acatadas e analisadas as contribuições dos alunos, valorizando-as, são estimulados os sentimentos de engajamento, percepção de competência e de pertencimento, além da persistência nos estudos, entre outras (BERBEL, 2011).

Diferente do método tradicional, no método ativo o aluno possui papel determinante na aprendizagem, possui suas experiência e opiniões apreciadas e, tem estimulada a curiosidade para refletir, problematizar, pesquisar, analisar e criar possíveis situações para a tomada de decisões. 
Dentro do cenário onde se demanda a formação de alunos capazes de atuar de forma significativa se torna interessante a adoção desse tipo de metodologia capaz de envolver o discente na atividade para que este busque autonomamente, soluções, resultados e para que possa avaliá-los.

No método ativo, o aluno assume um papel dotado de autonomia e o professor, que no método tradicional era o centro das atividades, torna-se um facilitador da construção do saber.Moran (2015, p. 24) enfatiza:

O papel do professor é mais o de curador e de orientador. Curador, que escolhe o que é relevante entre tanta informação disponível e ajuda a que os alunos encontrem sentido no mosaico de materiais e atividades disponíveis. Curador, no sentido também de cuidador: ele cuida de cada um, dá apoio, acolhe, estimula, valoriza, orienta e inspira. Orienta a classe, os grupos e a cada aluno. Ele tem que ser competente intelectualmente, afetivamente e gerencialmente (gestor de aprendizagens múltiplas e complexas). Isso exige profissionais melhor preparados, remunerados, valorizados. Infelizmente não é o que acontece na maioria das instituições educacionais.

Em que pese tal modificação na forma de atuação docente, ela não implica necessariamente em diminuição do trabalho do profissional, muito pelo contrário. Aqui o professor deve ter consciência das atividades que serão realizadas, dos conteúdos abordados e, sobretudo, das possíveis consequências do que propõe; o que pode demandar até muito mais preparo e planejamento quando comparado à aula tradicional.

\section{PRÁTICAS EDUCATIVAS E SUA IMPORTÂNCIA PARA A FORMAÇÃo INTEGRAL DO DISCENTE}

A educação, no Brasil, é marcada por deficiências históricas e estruturais, sobretudo por insistir em atualizações pautadas sempre em modelos previsíveis, industriais, em caixinhas. Modelos que mesmo apresentando melhores resultados, não promovem uma formação alinhada aos desafios do atual contexto que, cada vez mais, exige pessoas e profissionais que nas mais diversas situações mantenham a capacidade de criar e empreender (MORAN, 2015). No entanto, segundo o autor, nos últimos anos é possível destacar as buscas, tanto no setor privado quanto no público, por novas alternativas para as práticas educacionais. 
Vivemos em um momento marcado cada vez mais pela velocidade das mudanças. As verdades, entre elas as cientificas, são provisórias. A infinidade e poder das ferramentas tecnológicas de busca de informação fazem parte rotineira da vida, sobretudo dos mais jovens. E essa é uma realidade que já não permite que escola se mantenha com uma proposta de educação limitada a reprodução e transmissão de conteúdo.

Moran (2015) argumenta que a escola padronizada, que estabelece seus procedimentos de ensino e avaliação de forma igual a todos, atinge resultados previsíveis. Esses procedimentos ignoram o fato de que o conhecimento é baseado em competências cognitivas, pessoais e sociais, que não se adquirem da forma que convencionalmente vem sendo adotados pela escola. Mas, exigem proatividade, colaboração, personalização e visão empreendedora.

É neste sentido que Freire (2009), defende o respeito à autonomia do estudante, para ele a dignidade de cada um é um imperativo ético e não um favor que podemos ou não conceder a eles. Assim, o docente deve respeitar a curiosidade do aluno, promover sua inquietude e sua linguagem, e leva-los a refletir sobre os princípios éticos de nossa existência.

Em outras palavras é necessário transformar o espaço da sala de aula, em um ambiente em que a prática pedagógica seja promotora da construção de conhecimento, contribuindo de forma ativa para o desenvolvimento de uma atitude de autonomia intelectual e pessoal. A aprendizagem é assim entendida como um processo construtivo e não receptivo de conhecimento. É este também o pensamento defendido por Moran (2015) ao afirmar que, se queremos que os alunos sejam proativos, precisamos adotar metodologias em que os alunos se envolvam em atividades cada vez mais complexas, em que tenham que tomar decisões e avaliar os resultados. Para o autor, esse é um objetivo que só será alcançado quando o alunado for desafiado por intermédio de questões problemas que os motivem à resolução.

Os desafios bem planejados contribuem para mobilizar as competências desejadas, intelectuais, emocionais, pessoais e comunicacionais. Exigem pesquisar, avaliar situações, pontos de vista diferentes, fazer escolhas, assumir alguns riscos, aprender pela descoberta, caminhar do simples para o complexo (MORAN, 2015 p. 18). 
Atualmente, é exigido do cidadão, tanto na esfera pessoal como profissional, uma capacidade de enfrentar situações complexas e de se adaptar a elas em um contexto de rápidas transformações em que o mesmo precisa ser capaz de apresentar respostas atualizadas e criativas. Para tanto, é necessário que o estudante tenha uma participação efetiva na construção do conhecimento, com uma aproximação entre os conteúdos e conceitos estudados e sua vivência na sociedade.

Assim, não seria exagero afirmar que, no momento em que vivemos, já não é possível vislumbrar um trabalho pedagógico significativo sem o uso das metodologias ativas, ou seja, sua não utilização pressupõea não aproximação com as novas tendências educacionais.

Pensando nisso e entendendo a importância das novas tendências pedagógicas, apresentamos enquanto proposta metodológica um Roteiro de Estudo voltado à disciplina de história, destinado a estudantes do curso técnico em administração na modalidade integrada ao ensino médio, com a perspectiva de promover uma aprendizagem que possibilite uma participação ativa dos alunos na construção do conhecimento. O objetivo desta atividade é promover reflexões sobre as transformações ocorridas no mundo do trabalho, com a incorporação de modelos como o taylorismo e o fordismo, bases do modo de produção capitalista e das leituras apresentadas por Marx sobre esses modelos produtivos, por meio de conceitos como mais-valia e alienação do trabalho, bem como pensar a gestão a partir de uma perspectiva humanizada e pautada no desenvolvimento social.

Para tanto, o roteiro apresentado é dividido em quatro etapas, sendo:

1. Apresentação e Orientação da Pesquisa: o professor pode iniciar a aula, apresentando a proposta de trabalho e em seguida organizar os grupos de estudos (compostos de cinco integrantes), e orienta-los para a realização de um levanto e estudo bibliográfico voltados a fundamentação conceitual e histórica sobre taylorismo, fordismo, modo de produção capitalista, maisvalia e alienação do trabalho, e sobre os modelos empresarias mais conhecidos atualmente.

2. Estudo e discussão: na segunda etapa, será apresentado o filme "Tempos Modernos" (disponível em: www.youtube.com/watch?v=ieJ1_5y7fT8) e, 
em seguida, serão discutidos os temas identificando o alinhamento entre os conceitos pesquisados, as situações apresentadas no filme e os principais modelos empresariais da atualidade.

3. Aplicação do conhecimento: na terceira etapa do trabalho, cada grupo deve orientados pelos professores da administração (com acerto prévio) e embasados nas conclusões obtidas nos estudos anteriores - desenvolver um plano de negócio com diferenciais que, sem perder o caráter produtivo, se alinhem aos ideais do empreendedorismo social, levando em consideração o desenvolvimento social local e a valorização de seu pessoal.

4. Exposição de resultados: após a conclusão do plano de negócio, cada grupo deve criar um vídeo de curta duração promovendo o marketing de sua ideia.

A proposta aqui apresentada é uma alternativa para o desenvolvimento de práticas pedagógicas que coloquem o estudante na condição de protagonista da construção de seu conhecimento. Assim, entendemos a atividade aqui descrita enquanto uma possibilidade de construção ativa de conhecimento por parte do estudante e que dá a possibilidade de perceber de maneira menos abstrata os conteúdos, vislumbrando sua aplicação prática, o que torna didaticamente mais concreto seu aprendizado.

\section{CONSIDERAÇÕES FINAIS}

A Educação Profissional e Tecnológica apresenta-se na atual conjuntura, como uma como uma alternativa em potencial para a educação brasileira. Para tanto, alguns desafios precisam ser superados, entre esses desafios, o principal é o de promover de fato uma formação humana integral, mas para que se alcance esse objetivo é necessário que se desenvolvam métodos de ensino que sejam capazes de articular os conhecimentos técnicos e gerais e que, acima de tudo, sejam capazes de pensar o conhecimento como fruto de uma construção e não de simples transmissão e para isso o estudante precisa ser colocado como protagonista desse processo.

As atividades que possibilitam aos alunos a busca de construção ativa do conhecimento são não só mais estimuladoras, são didaticamente mais eficientes. Quando apresentados desafios aos alunos, situações problemas que vinculem o 
conteúdo com suas futuras práticas profissionais, temos o desenvolvimento de práticas pedagógicas que se caracterizam como motivadoras para os estudantes que manifestam claramente maior interesse pelos conteúdos desenvolvidos. Essas práticas menos convencionais quebram a rotina de sala de aula que, por serem, em certa medida, repetitivas em relação aos métodos de ensino, acabam por se tornarem desinteressantes aos alunos.

Por isso, entendemos as Metodologias Ativas como propostas com especial importância no atual contexto educacional. Em suma, um profissional ou instituição de Educação Profissional e Tecnológica que não reconheça essa importância e não busque desenvolver metodologias desse seguimento, prendendo-se ainda às convencionais práticas educativas que não acompanham o ritmo das mudanças desempenhadas na sociedade e não estimulam a criatividade e inquietação discente dificilmente conseguirão atingir seu objetivo maior que é a formação humana integral e estarão se distanciando cada vez mais das novas tendências educacionais.

\section{REFERÊNCIAS}

BARBOSA, E. F.; MÜLLER, M. C. Currículo, escola e letramento : o que isso tem a ver com a formação do cidadão?.Revista on line de Política e Gestão Educacional, p. 20-31, 2014.

BRASIL. Observatório do PNE. Disponível em <http://www.observatoriodopne.org.br/metas-pne/11-educacao-profissional>. Acesso em: jun. 2018.

DURÃES, Marina Nunes. Educação Técnica e Educação Tecnológica: múltiplos significados no contexto da Educação Profissional. Educação e Realidade, v. 34, p. 159-175, n. 2009.

BERBEL, N. A. N. As metodologias ativas e a promoção da autonomia de estudantes. Semina: Ciências Sociais e Humanas, v. 32, n. 1, p. 25-40, 2011.

DALLABONA, C. A.; MAYNARDES, T.; FARINIUK, D. EPT no Brasil : histórico , panorama e perspectivas ept in brazil : History, panorama and prospects. Revista do Programa de Pós-graduação em Educação - Mestrado - Universidade do Sul de Santa Catarina UNISUL, v. 10, p. 46-65, 2016.

DARIVA, N. G.; BENETTI, C. C. Formação docente e experiência: possibilidades para pensar o outro e a diferença Neyha Guedes Dariva. REP's - Revista Even. Pedagóg., v. 2, p. 919-930, 2016. 
FARIAS, H.; MAIA, C. A aula de direito e a escola tradicional : Uma análise crítica das características da tendência e suas consequências no ensino jurídico. [s.l: s.n.]. Disponível em: $<$ http://fadipa.educacao.ws/ojs-2.3.33/index.php/cjuridicas/article/viewFile/161/pdf>. Acesso em: abr. 2018.

FREIRE, P. Pedagogia da Autonomia. 36. Ed. São Paulo: Paz e Terra, 2009.

LIMA, S. S.; MARIA ZÉLIA MAIA DE SOUZA. Estratégias para o e jovens desvalidos no Brasil (1865-1905). Práxis \& Saber, v. 8, p. 17-34, 2017.

MORAN, J. Mudando a educação com metodologias ativas. In: SOUZA, Carlos Alberto de; MORALES, Ofelia Elisa Torres (orgs.). Convergências Midiáticas, Educação e Cidadania: aproximações jovens. Coleção Mídias Contemporâneas. vol. II. Ponta Grossa: Foca Foto-PROEX/UEPG, 2015. 